\title{
Optical (DRUV-VIS) and Magnetic (EPR) Behavior of Synthetic Melanins
}

\author{
Júlio César Pereira dos Santos ${ }^{\mathrm{a}}$, Cláudia Eliana Bruno Marino ${ }^{\mathrm{b}}$,

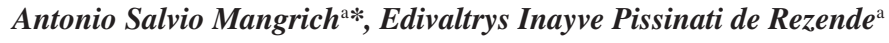 \\ a Departamento de Química, Universidade Federal do Paraná - UFPR, \\ CEP 81531-990 Curitiba, PR, Brazil \\ bepartamento de Engenharia Mecânica, Universidade Federal do Paraná - UFPR, \\ CEP 81531-990, Curitiba, PR, Brazil
}

Received: April 1, 2011; Revised: November 24, 2011

\begin{abstract}
The properties of melanins prepared from L-dopa oxidation by both chemical and electrochemical methods are reported, searching for a material with more intense optical absorption in the visible region. The characterization of the samples have been done by cyclic voltammetry (CV), cronoamperometry (CA), Fourier transformed infrared spectroscopy (FTIR), electron paramagnetic resonance spectroscopy (EPR) and diffuse reflectance ultraviolet-visible spectroscopy (DRUV-VIS) techniques. The electrochemical method enhanced the organic free radical (spin) concentration and the absorption intensity in the visible region of the spectrum. The DRUV-VIS technique along with mathematical tools, such as the Kubelka-Munk remission function, were good options for the characterization of the final products.
\end{abstract}

Keywords: EPR spectroscopy, Kubelka-Munk, optical properties, electrochemical techniques

\section{Introduction}

Melanins constitute a widespread class of pigment in nature, commonly formed by oxidative polymerization of cathecolic species derived from tyrosine ${ }^{1}$. In soil, fungal and actinomycete melanins are thinking to be an important precursor for the humic substance formation ${ }^{2,3}$. In humans, melanins are present in the skin and in certain brain structures like the substantia nigra and red nucleus, and in the inner ear ${ }^{4}$. The physico-chemical characteristics of melanins turn them quite complex to be studied by standard methods. The biological functions of melanins are now more noticeably and understandable. It is believed that in many pigment cells, melanin may act as a powerful antioxidant via, for example, for heavy metal sequestration ${ }^{5}$. Natural melanins contain a wide variety of bound metals in vivo, and are unusual among the biopolymers because of the highly polyionic, cross-linked, and heterogeneous polymers, whose bonding patterns likely vary in subtle ways. This amorphous dark pigment, highly hygroscopic is obtained by oxidation of molecules that contain catechol function such dopamine, L-dopa ${ }^{6}$. Previously, melanins were considered stable compounds due to its small changes during both acid and basic hydrolysis and low solubility ${ }^{7}$. Nowadays melanins are faced as heterogeneous polymers containing a mix of 5,6-di-hydroxiindol moieties, with different oxidation states and attached randomically at pirrol moieties by $\mathrm{C}-\mathrm{C}$ bonding ${ }^{8}$. Many studies have been done about the melanins polymerization mechanism to understand its biosynthesis ${ }^{9}$. Some chromatographic,

*e-mail: mangrich@ufpr.br electrochemical and spectro-electrochemical studies ${ }^{10-12}$, besides capillary electrophoresis ${ }^{13}$ and photoelectron spectroscopy (XPS) studies ${ }^{14}$ have been employed to determine the melanin formation mechanism. The L-dopa (3, 4-dihydroxiphenilalanine) was used as a model compound because its structure is similar to monomers found into natural melanin structure ${ }^{15}$ allowing the biomimetic studies about it $\mathrm{it}^{8,16}$.

In this study two synthetic melanins were obtained from both chemical and electrochemical oxidation of L-dopa, in order to observe differences in light absorption by the prepared materials on the visible region. DRUV-VIS technique along with the Kubelka-Munk remission function was used to distinguish between the absorption properties of the two synthesized solid melanins. The electron paramagnetic resonance (EPR) study allowed determination of organic free radical (OFR) concentration (spin. $\mathrm{g}^{-1}$ ) of the two complex organic materials ${ }^{17,18}$. The OFR was also identified by the EPR spectroelectrochemistry technique ${ }^{19}$.

\section{Experimental Details}

\subsection{Chemical reagents and samples preparation}

All chemical reagents and solvents were of high purity degree and used without prior purification. Distilled and deionized water was used to prepare all aqueous solutions. The melanins samples were prepared by oxidation of L-dopa by both, oxygen of the air (SM1) and electrochemically (SM2). The SM1 sample was obtained dissolving $50 \mathrm{mg}$ of 
L-dopa in $10 \mathrm{~mL}$ of aqueous phosphate/ $\mathrm{NaOH} 0.1$ mol.L ${ }^{-1}$ $(\mathrm{pH}=6.8)$ solution and stirred at room temperature. After a few minutes, a black material (SM1) was formed as a suspension, which was filtered, dried at $45-50{ }^{\circ} \mathrm{C}$ and analyzed. To obtain the SM2 sample, $50 \mathrm{mg}$ of L-dopa were dissolved in $10 \mathrm{~mL}$ of phosphate/NaOH 0.1 mol.L ${ }^{-1}$ aqueous solution $(\mathrm{pH}=6.8)$ into an electrochemical cell that was fluxed and kept under argon atmosphere. The electrochemical oxidation process was performed by application of controlled electric potential at $+620 \mathrm{mV}$ for 5 minutes. The formed suspension was isolated by the same procedure of the SM1 Sample.

\subsection{Electrochemical measurements}

The electrochemical synthesis of the SM2 sample was carried out using a Potenciostat-Galvanostat system (Microquimica $^{\circledR}$, model MQPG-01) connected to a threeelectrode electrochemical cell. The working and counter electrodes were Pt wire and Pt spiral, respectively. All potentials were measured against an $\mathrm{Ag} / \mathrm{AgCl}$ electrode. The buffered aqueous electrolytic solution was prepared using potassium phosphate and sodium hydroxide, both in 0.1 mol. $\mathrm{L}^{-1}$ concentration $(\mathrm{pH}=6.8)$. Before the experiments, the electrolytic solution was kept at $\sim 25^{\circ} \mathrm{C}$, and under an argon atmosphere. Voltammetric profiles were obtained at initial potential of $-0.6 \mathrm{~V}$ and final potential of $1.0 \mathrm{~V}$, at a sweep rate of $100 \mathrm{mV} . \mathrm{s}^{-1}$.

\subsection{EPR spectroelectrochemistry}

EPR spectroelectrochemistry was performed in a BRUKER $^{\circledR}$ ESP 300 E spectrometer using the X-band $(\sim 9.5 \mathrm{GHz})$ with modulation frequency of $100 \mathrm{kHz}$ at room temperature $\left(\sim 25{ }^{\circ} \mathrm{C}\right)$ in a quartz flat cell under inert atmosphere of argon. EPR spectra were taken using the first derivative mode for the $500 \mathrm{mT}$ range. The black product formed was dried at $45-50{ }^{\circ} \mathrm{C}$ and its spectroscopic characterization was performed. Fourier transforms infrared spectroscopy (FTIR).

The FTIR spectra were registered in a Bomem Hartmann \& Braun series MB100 spectrophotometer from pellets prepared and pressed from mixtures with approximately $1 \mathrm{mg}$ of the sample and $99 \mathrm{mg}$ of $\mathrm{KBr}$ spectroscopic grade. For each spectrum, 128 scans were accomplished with resolution of $2 \mathrm{~cm}^{-1}$ in the spectrum range from 4000 to $400 \mathrm{~cm}^{-1}$.

\subsection{Diffuse reflectance ultraviolet-visible spectroscopy (DRUV-VIS)}

SM1 and SM2 melanin solid state samples were analyzed by the DRUV-VIS technique. The analyses of solid samples were performed using a Shimadzu UV2401PC spectrophotometer, equipped with a 240-52454-01 integration sphere accessory. The solid material was ground in a pan grinder to 200 mesh size. Then, this material was analyzed after being compressed carefully into the spectrometer cell. The DRUV-VIS spectra were converted to the Kubelka-Munk remission function defined by, $f(K M)=(1-R)^{2} / 2 R=k / s$, where $R$ is the reflectance, $k$ is the absorption coefficient, and $\mathrm{s}$ is the scattering coefficient ${ }^{9,11}$.

\section{Results and Discussion}

Initially, cyclic voltammetry (Figure 1) was used to study the electrochemical behavior of L-dopa under the electrical applied potential. Figure 1 shows a first redox pair in +217 and $+386 \mathrm{mV}$ and one shoulder in $+628 \mathrm{mV}$ and one reduction signal in $-69 \mathrm{mV}$ versus $\mathrm{Ag} / \mathrm{AgCl}$. This difference between oxidation and reduction peaks $(386-217 \mathrm{mV})$ of $169 \mathrm{mV}$ suggests that redox system is irreversible ${ }^{12}$. Some authors $^{8}$ described that anodic peaks presented on the cyclic voltammogram cannot be assigned totally to L-dopa oxidation. During the oxidation there are the formation of dopaquinones that may be partially reduced to L-dopa again and standing in acidic $\mathrm{pH}$. It suggests a nucleophilic attack to the deprotonated amino group resulting in an indolic product ${ }^{20}$. It was visually observed an orange color on the electrode surface indicating a complete oxidation of L-dopa ${ }^{21}$.

Regarding to EPR spectroelectrochemistry, the spectra in the sweep width of $500 \mathrm{mT}$ (Figure 2) presents only an intense line with the $g$-factor $(g=2.0036)$ typical of organic free radical (OFR). The spectra in the sweep width of $5 \mathrm{mT}$, carried out at room temperature (not shown), reveals that

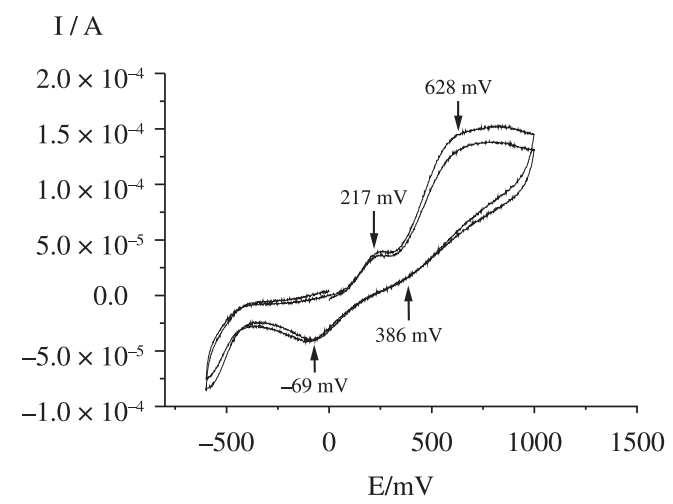

Figure 1. Preliminary voltamogram of L-dopa in phosphate buffer solution $\left(0.1 \mathrm{~mol} . \mathrm{L}^{-1}\right.$ at $\left.\mathrm{pH}=6.8\right)$ under argon inert atmosphere. Range from -0.600 to $1.0 \mathrm{~V}$ at $100 \mathrm{mV} . \mathrm{s}^{-1}$.

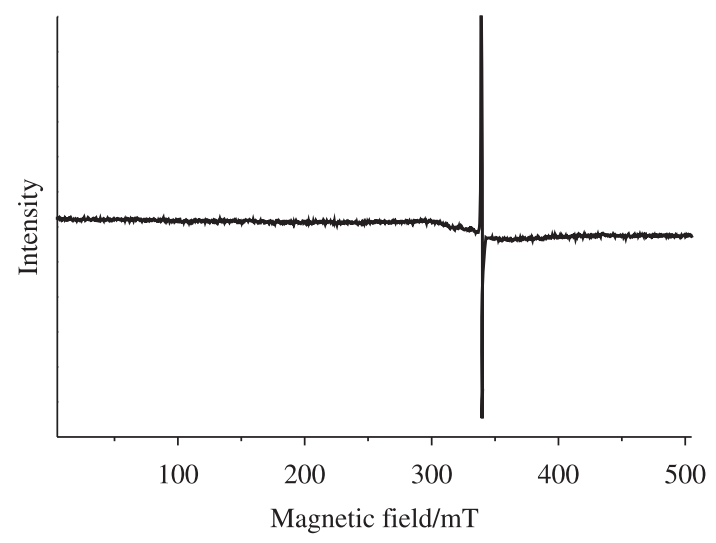

Figure 2. EPR spectroelectrochemistry in magnetic field sweep width of $500 \mathrm{mT}$ during the electrochemical oxidation of L-dopa by cronoamperometry in potential controlled at $+620 \mathrm{mV}$ versus ENH and electrolyte solution of phosphate buffer 0.1 mol.L ${ }^{-1}$ at $\mathrm{pH}=6.8$ under argon inert atmosphere. 
spin density (spin. $\mathrm{g}^{-1}$ ) of SM2 is higher than that of SM1 (Table 1). The $\mathrm{g}$ factor values are similar, $\mathrm{SM} 1, \mathrm{~g}=2.0035$ and $\mathrm{SM} 2, \mathrm{~g}=2.0036$. Both samples present the OFR near to the oxygen atoms of the chemical structure, which suggests the involvement of these atoms in the radical formation. The line widths also are different, with SM1, $\Delta \mathrm{H}_{\mathrm{pp}}=0.41 \mathrm{mT}$ and $\mathrm{SM} 2=0.35 \mathrm{mT}$.

Figure 3 shows the Kubelka-Munk function for the spectral responses, by DRUV-VIS spectroscopy, obtained at wavelengths from 250 to $800 \mathrm{~nm}$. The spectral curves showed some similar characteristics, with common absorptions at 260 and $310 \mathrm{~nm}$. The absorption at $340 \mathrm{~nm}$ in the SM1 sample appears as a shoulder of the band at $310 \mathrm{~nm}$ in the SM2 sample. The spectrum of the SM1 sample presents a continuous decrease of the absorption intensities from $340 \mathrm{~nm}$ to the end, with small maxima at 360, 420 and $500 \mathrm{~nm}$. The SM2 sample presents several small peaks at the same region of the spectrum and a broad absorption band with the maximum at $530 \mathrm{~nm}$ and extended from about 450 to $600 \mathrm{~nm}$. The absorption bands in the range of 250 to $340 \mathrm{~nm}$ correspond to transition of electrons from $\pi$ bonding to $\pi^{*}$ antibonding orbitals. These absorptions are indicative of the polymerization degree and the presence of polyaromatic and/or conjugated unsaturated aliphatic structures. The SM2 sample with the broad absorption band at $530 \mathrm{~nm}$ probably presents a more conjugated chemical structure.

Figure 4 presents the infrared spectra in the range of 4000 to $400 \mathrm{~cm}^{-1}$. The SM1 sample spectrum presents absorption bands between 3600 and $3100 \mathrm{~cm}^{-1}$, typical of the -O-H and -N-H stretching groups undergoing intermolecular hydrogen bonding. The absorption band at $1725 \mathrm{~cm}^{-1}$ is attributed to the $\mathrm{C}=\mathrm{O}$ stretching of carboxylic groups. This band is more evident for the SM1 than for the SM2 sample suggesting an incomplete melanin formation by the oxidation chemical method. For the SM1 sample, the strong band at $1645 \mathrm{~cm}^{-1}$ is attributed to the asymmetrical stretching of the carboxylate groups, while the symmetrical vibration mode is observed as a weak band at $1400 \mathrm{~cm}^{-1}$. The SM2 sample presents only a broad band at $1645 \mathrm{~cm}^{-1}$ that could be attributed to the bending vibration of water molecules, in addition to the broad band above around $3100 \mathrm{~cm}^{-1}$, which is also attributed to the stretching of water $\mathrm{O}-\mathrm{H}$ groups with a diversity of hydrogen bonding. Absorption at $1090 \mathrm{~cm}^{-1}$ could be assigned to the C-O-C asymmetrical stretching vibration of ethers that are characterized by a strong band in this region. Otherwise, SM2 sample presented a broad band (not showed) around $2350 \mathrm{~cm}^{-1}$, suggesting an overtone shifted from the $1090 \mathrm{~cm}^{-1}$ peak $^{22,23}$. These results indicate that the oxidative electrochemical process to produce melanins is more effective and easily controlled.

Table 1. EPR spectroscopic parameters (line width, $(\Delta \mathrm{Hpp})$, $\mathrm{g}$-factor and spin density (spin. $\left.\mathrm{g}^{-1}\right)$ ) of the synthetic melanins, SM1 and SM2.

\begin{tabular}{lll}
\hline Parameters & SM1 & SM2 \\
\hline$\Delta \mathrm{H}_{\mathrm{pp}}(\mathrm{mT})$ & 0.41 & 0.35 \\
$\mathrm{~g}$-factor $(\mathrm{OFR})$ & 2.0035 & 2.0036 \\
Spin. $^{-1}\left(10^{16}\right)$ & 7.5 & 9.4 \\
\hline
\end{tabular}

Figure 5 shows as the L-dopa concentration directly affects the current peak magnitudes. Voltammetric profiles (from $-0.6 \mathrm{~V}$ up to $+1.0 \mathrm{~V}$ versus $\mathrm{Ag} / \mathrm{AgCl}$ at $100 \mathrm{mV} . \mathrm{s}^{-1}$ )

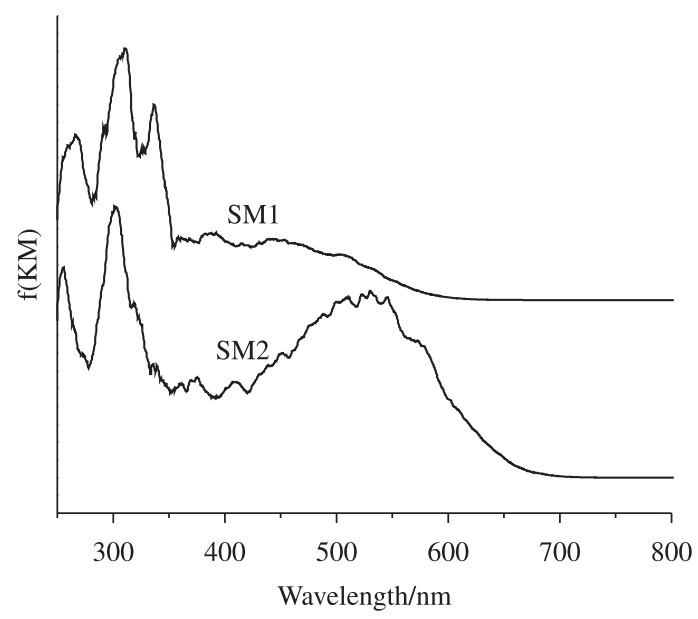

Figure 3. Ultraviolet spectra of SM's in solid state in the range of 240 to $800 \mathrm{~nm}$ presented in the Kubelka-Munk remission function mode $\left(f(K M)=(1-R)^{2} / 2 R\right)$.

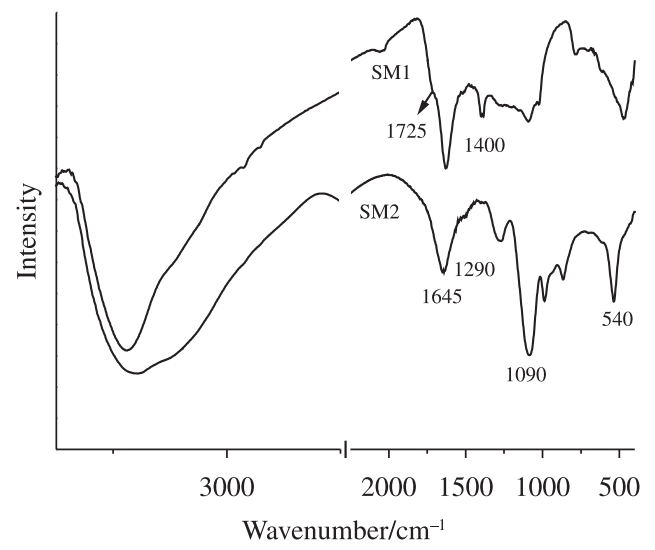

Figure 4. Infrared spectra of SM's in $\mathrm{KBr}$ pastille. Range from 400 to $4000 \mathrm{~cm}^{-1}$.

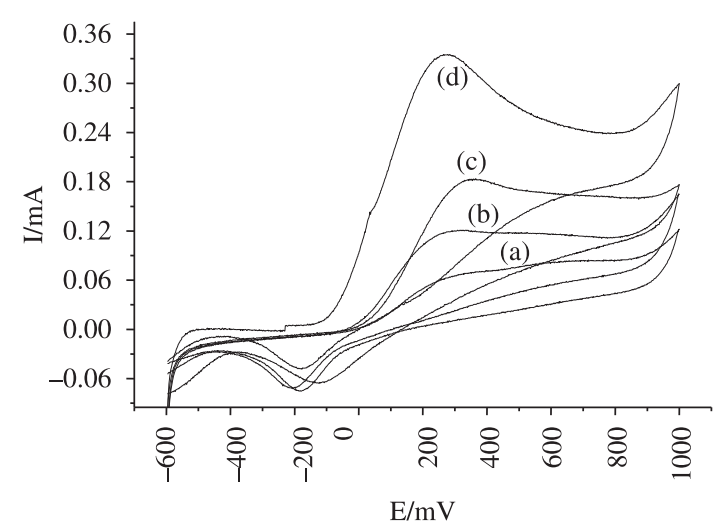

Figure 5. Cyclic voltamograms between, $-0.6 \mathrm{~V}$ and $1.0 \mathrm{~V}$ versus $\mathrm{Ag} / \mathrm{AgCl}$ of L-dopa in phosphate buffer aqueous solution ( $\mathrm{pH} 6.8$ ) for concentrations: a) $5 \mathrm{mg}$, b) $10 \mathrm{mg}$, c) $30 \mathrm{mg}$ and d) $50 \mathrm{mg}$ per $100 \mathrm{~mL}$ at $100 \mathrm{mV} \cdot \mathrm{s}^{-1}$. 
are shown, corresponding to the L-dopa oxidation to melanin on Pt electrode using L-dopa concentrations of $5,10,30$ and $50 \mathrm{mg}$ per $100 \mathrm{~mL}$ of the electrolyte. As can be seen, the I versus E voltammograms present a typical profile of the oxidation and reduction processes of this organic molecule, e.g., a reduction peak around $-0.18 \mathrm{~V}$ and an oxidation peak around $0.27 \mathrm{~V}$ (versus $\mathrm{Ag} / \mathrm{AgCl}$ ). When the L-dopa concentration is varied, it is possible to observe a reasonable increase of the anodic peak with the increase of L-dopa concentration in phosphate buffer solution, e.g., from 0.061 to $0.33 \mathrm{~mA}$. It means that the anodic charges involved in this oxidation process increases and consequently, the thickness of the oxidized product also increases. These charges could be obtained by integration of the corresponding I versus $\mathrm{E}$ curves.

\section{References}

1. Golounin AV and Seliutin GE. Effect of chemical treatment on paramagnetic properties of melanin. Russian Journal of applied chemistry. 1996; 69(4):583-586.

2. D'amato RJ, Lipman ZP and Snyder SH. Selectivity of the parkinsonian neurotoxin MPTP: toxic metabolite MPP + binds to neuromelanin. Science. 1986; 231:987-989. PMid:3080808. http:// dx.doi.org/10.1126/science.3080808

3. Stainsack J. Estudo de estruturas de melaninas sintéticas através da interação com íons metálicos paramagnéticos. [Tese]. Curitiba: Universidade Federal do Paraná; 1998.

4. Piccolo A. Humus and soil conservation. In: Piccolo A. Humic Substances in Terrestrial Ecosystems. Amsterdam: Elsevier; 1996. http://dx.doi.org/10.1016/B978-044481516-3/50006-2

5. Cantarow A and Schepartz B. Bioquímica. Livraria Ateneu;1968. p. 833.

6. Cabanes J, Garcia-Canovas F and Lozano JA. A kinetic-study of the melanization pathway between L-tirosine and dopachrome. Biochimica et Biophysica Acta. 1987; 923(2):187-195. http://dx.doi. org/10.1016/0304-4165(87)90003-1

7. Wilczok T, Bilinska B, Buszman E and Kopera M. Spectroscopic studies of chemically modified synthetic melanins. Archives of Biochemistry Biophysics. 1984; 231(2):257-262. http://dx.doi. org/10.1016/0003-9861(84)90386-2

8. Robinson GM, Iwuoha EI and Smyth MR. Characterisation of electrosynthetic L-dopa-melanin films by electrochemical and spectroelectrochemical techniques. Electrochimica Acta. 1998; 43(23):3489-3496. http://dx.doi.org/10.1016/S00134686(98)00096-6

9. Napolitano A, Pezella A, D'Ischia M and Prota G. New pyrrole acids by oxidative degradation of eumelanins with hydrogen peroxide. Further hints to the mechanism of pigment breakdown. Tetraedron. 1996; 52(26):8775-8780. http://dx.doi. org/10.1016/0040-4020(96)00418-8

10. Zhang XJ, Wang CF and Zhou XY. Voltammetry of dihydroxyphenylalanine (L-dopa) using a nafion-coated carbon-fiber ultramicroelectrode array. Analytica Chimica Acta. 1992; 265(1): 27-34. http://dx.doi.org/10.1016/0040-4020(96)00418-8

11. Rubianes MD and Rivas GA. Highly selective dopamine quantification using a glassy carbon electrode modified with a melanin-type polymer. Analytica Chimica Acta. 2001; 440(2):99108. http://dx.doi.org/10.1016/S0003-2670(01)01059-5

12. Serpentini CL, Gauchet C, De Montauzon D, Comtat M, Ginestar $\mathrm{J}$ and Paillous N. First electrochemical investigation of the redox properties of dopa-melanins by means of a carbon paste electrode. Electrochimica Acta. 2000; 45(10):1663-1668. http://dx.doi. org/10.1016/S0013-4686(99)00388-6

13. Oshea TJ, Telting-Diaz MW, Lunte SM, Lunte CE and Smyth MR. Capillary electrophoresis electrochemistry of microdialysis samples for pharmacokinetic studies. Electroanalysis. 1992; 4(4):463-468. http://dx.doi.org/10.1002/elan.1140040412

\section{Conclusion}

Results obtained have shown that spectroscopic and electrochemical techniques used in the melanin characterization were effective to assess qualitatively the two samples. The EPR spectroelectrochemistry clearly presented only one signal of OFR due to the melanin oxidation and the $o$-benzosemiquinone formation along the process. These measures are confirmed also to the FTIR spectra. These results suggest that the electrochemical pathway is more effective than chemical oxidation, allowing better control of the process.

\section{Acknowledgements}

The authors are grateful to the CNPq reserch fellowship, PADCT, FINEP and Fundação Araucária, for financial supports.

14. Stern DA, Salaita GN, Lu F, McCargar JW, Batina N, Frank DG et al. Studies of L-dopa and related compounds adsorbed from aqueous solutions at $\mathrm{Pt}(100)$ and $\mathrm{Pt}(111)$ : electron energyloss spectroscopy, auger spectroscopy, and electrochemistry. Langmuir. 1988; 4(3):711-722. http://dx.doi.org/10.1021/ la00081a037

15. Reszka KJ and Chignell CF. EPR and spin-trapping investigation of free radicals from the reaction of 4-methoxybenzenediazonium tetrafluoroborate with melanin and melanin precursors. Journal of the American Chemical Society. 1993; 115(17):7752-7760. http:// dx.doi.org/10.1021/ja00070a021

16. Kumaraswamy BE, Sherigara BS, Subrahmanyam EVS, Venkateswaran G. Cyclic voltammetric behavior of L-dopa [3-(3,4-dihydroxyphenyl)-L-alanine] at a platinum electrode in pyrophosphate media. Bulletin of Electrochemistry. 2000; 16(12): 533-536.

17. Guimarães E. Caracterização química, espectroscópica e por análise térmica de ácidos húmicos e vermicompostos obtidos de estercos de diferentes animais. [Tese]. Curitiba: Universidade Federal do Paraná; 1997.

18. Mangrich AS, Lermen AW, Santos EJ, Gomes RC, Coelho RRR, Linhares LF et al. Electron paramagnetic resonance and ultravioletvisible spectroscopic evidence for coppe porphyrin in actinomycete melanins. Biology and Fertility of Soils. 1998; 26(4):341-345. http:// dx.doi.org/10.1007/s003740050386

19. Dos Anjos A, Bortoluzzi AJ, Szpoganicz B, Caro MSB, Friedermann GR, Mangrich AS et al. Synthesis, characterization and structure of a new zinc(II) complex containing the hexadentate N,N',N,N'bis[(2-hydroxy-3,5-di-tert-butylbenzyl) (2-pyridylmethyl)]ethylenediamine ligand: Generation of phenoxyl radical species. Inorganica Chimica Acta. 2005; 358(11):3106-3114. http://dx.doi. org/10.1016/j.ica.2005.04.043

20. Rein FN, Rocha RC and Toma HE. Catecholamine complexes of ruthenium-edta and their redox chemistry. Journal of Inorganic Biochemistry. 2001; 85(2-3):155-166. http://dx.doi.org/10.1016/ S0162-0134(01)00194-5

21. Dos Santos JCP and Mangrich AS. Síntese e caracterização de melanina por oxidação eletroquímica da L-dopa. In: Anais do X Encontro de Química da Região Sul - SBQ - Sul; 2002; Joinville. SBQ; 2002. v. 1, p. 291.

22. Paim S, Linhares LF, Mangrich AS and Martin JP. Characterization of fungal melanins and soil humic acids by chemical-analysis and infrared-spectroscopy. Biology and Fertility of Soils. 1990; 10(1): 72-76.

23. Miikki V, Senesi N and Hänninen K. Characterization of humic material formed by composting of domestic and industrial biowastes. 2. Spectroscopic evaluation of humic acid structures. Chemosphere. 1997; 34(8):1639-1651. http://dx.doi.org/10.1016/ S0045-6535(97)00021-0 